\title{
FORMAÇÃO INICIAL E CONTINUADA DE PROFESSOR FACE ÀS TECNOLOGIAS DIGITAIS
}

\author{
Sandro Luis Silva* \\ Cirlei Irabel da Silva Paiva
}

\begin{abstract}
RESUMO: Este artigo propõe uma reflexão sobre as interfaces entre formação inicial e continuada de professor e a utilização das tecnologias nesse processo. As tecnologias estão cada vez mais presentes no cotidiano dos indivíduos e, consequentemente, devem fazer parte do processo de ensinoaprendizagem para que a escola se aproxime mais da realidade em estão inseridos os sujeitos que dela participam. Por meio de uma abordagem qualitativa, trazemos conceitos sobre discurso, multimodalidade, letramento digital e formação de professores e, a partir desses, sugerimos o uso de dois aplicativos para a construção do conhecimento, seja na formação inicial, seja na continuada. A base teórica para este estudo foi Perrenoud (2000), Kensky (2014), Carmo (2003) e Xavier (2007) sobre o letramento digital, além de Dioníso e Vasconcelos (2013) e Maingueneau (2015) no que se refere à multimodalidade. Por darmos uma abordagem à interface entre a formação de professor e novas tecnologias, valemo-nos, também, de documentos oficiais, como o Parecer 9/2001 do Conselho Nacional de Educação, os Parâmetros Curriculares Nacionais (1998) e Leis de Diretrizes e Bases (1996), que subsidiam nossas reflexões. Pelo que apresentamos neste artigo, é possível afirmar que educação de qualidade depende de uma formação que concilie teoria e prática, levando o futuro professor a captar melhor as condições sociais, culturais, intelectuais de sua própria prática. E esse fato refletirá na prática docente na escola básica.
\end{abstract}

PALAVRAS-CHAVE: Formação de professor; Letramento Digital; Tecnologias digitais.

\footnotetext{
* Doutor em Língua Portuguesa pela Pontifícia Universidade Católica de São Paulo (Puc-SP). Professor Adjunto da Universidade Federal de São Paulo (Unifesp).

** Doutora em Ciências Sociais pela Pontifícia Universidade Católica de São Paulo (Puc-SP). Professora de Metodologia da Pesquisa e Ensino da Universidade Paulistana.
} 


\section{Palavras Iniciais}

Muito se tem discutido sobre a inserção das novas tecnologias no processo de ensino-aprendizagem, como também na formação inicial e continuada de professores das diversas áreas do conhecimento. Vivemos em um momento em que é inconcebível não pensar a utilização das tecnologias na educação, seja na básica, seja na superior, se quisermos fazer com que a instituição escolar esteja próxima da realidade dos sujeitos que dela participam.

Desde a publicação dos Parâmetros Curriculares Nacionais do Ensino Médio (PCNM, 2000), em 1998, já se vislumbrava novas metodologias para as práticas pedagógicas, inclusive com a inserção de tecnologias, não necessariamente as digitais, tendo em vista o contexto em que foram publicados. No entanto, há se pensava em proporcionar, ainda que timidamente, uma dinâmica nas atividades escolares que tornasse o aluno um sujeito ativo no processo de ensino-aprendizagem. Segundo o documento oficial,

As novas tecnologias da comunicação e da informação permeiam o cotidiano, independente do espaço físico, e criam necessidades de vida e convivências que precisam ser analisadas no espaço escolar. A televisão, o rádio, a informática, entre outros, fizeram com que os homens se aproximassem por imagens e sons de mundos antes inimagináveis. (BRASIL, 2000, p. 11-12)

Como se pode observar, naquela época já havia uma preocupação em trazer para os bancos escolares novas metodologias que privilegiassem a inserção de ferramentas que fizessem parte das tecnologias da comunicação e da informação. Para que essas ferramentas sejam utilizadas adequadamente no processo de ensino-aprendizagem, o professor precisa ser bem (in)formado, de modo que possua os diferentes letramentos de modo a atender às expectativas dos alunos com quem trabalha, fazendo com que o processo de ensino-aprendizagem seja mais significativo para os sujeitos.

Dentro de uma perspectiva em que novos paradigmas se configuram na prática pedagógica, é preciso entender que educação não se resume no ato de transmissão de co- 
nhecimento, ou, como dizia Paulo Freire, não pode se configurar em uma educação bancária. Fazem-se necessárias reflexões sobre as mudanças que o mundo contemporâneo tem exigido dos sujeitos que participam do processo de ensino-aprendizagem - professores, professores-formadores, alunos, coordenadores, diretores, dentre outros. Nos limites deste artigo, vamos nos ater à formação inicial do professor para a escola básica. Acreditamos que um professor bem formado, ou seja, preparado para lidar com as diversidades que encontrará na educação básica, é essencial para que o exercício docente obtenha êxito, fazendo com que a aprendizagem seja significativa para todos que dela participam.

Acreditamos que a formação inicial e continuada precisa estar envolvida com fatores sociais, políticos, econômicos e tecnológicos, os quais permeiam a sociedade em que os sujeitos estão inseridos. Por este motivo, acreditamos que a universidade não pode se eximir de desenvolver a competência do futuro docente em relação ao letramento digital.

Durante nossa prática docente - seja na educação básica, seja na formação de professores - deparamo-nos com dificuldades de muitos professores em lidar com os recursos oferecidos pelas novas tecnologias. Diante das dificuldades encontradas, acreditamos ser necessário reflexão sobre a interface entre a formação inicial do professor e o uso das tecnologias digitais no processo de ensino-aprendizagem.

Para atingir o objetivo proposto por nós, dividimos este artigo em duas grandes seções: na primeira trazemos reflexões sobre o letramento digital e a formação inicial do professor. Na segunda, sugerimos duas atividades que podem ser adotadas pelo professorformador, a fim de tornar os futuros professores que atuarão na escola básica competentes para a inserção das tecnologias digitais no processo de ensino-aprendizagem.

O estudo pauta-se em Pinheiro (2012) no que diz respeito à atividade colaborativa. No tocante ao discurso, voltamos nosso olhar para Maingueneau (2015). As considerações sobre o letramento digital, embasamos nossas considerações em Perrenoud (2000), Kensky (2014), Carmo (2003) e Xavier (2007). Por darmos uma abordagem à interface entre a formação de professor e novas tecnologias, valemo-nos, também, de documentos oficiais, 
como o Parecer 9/2001 do Conselho Nacional de Educação, os Parâmetros Curriculares Nacionais (1998) e Leis de Diretrizes e Bases (1996).

Evidentemente que, tendo em vista a complexidade do assunto, o artigo apresenta algumas reflexões sobre as possíveis interfaces entre o uso das novas tecnologias e a formação de professor, sem ter a pretensão de apontar "receitas" ou único caminho para o uso das tecnologias no processo de ensino-aprendizagem.

\section{A formação inicial do professor e o letramento digital}

Cada vez mais a internet e todos os seus recursos se fazem presentes nas mais diversas esferas de atividade humana e, dentre elas, a pedagógica. A instituição escola também é chamada para atender à demanda da sociedade, a fim de levar os educandos ao desenvolvimento das competências e habilidades necessárias para a construção do conhecimento. No entanto, para que esse papel seja realizado com eficácia, é preciso que o professor tenha, também, o letramento digital.

O docente, numa perspectiva educacional em que a construção do conhecimento deixa de ser aquela centralizada no professor e passa a ser realizada de forma colaborativa, passa a exercer o papel de mediador no processo de ensino-aprendizagem. De acordo com Pinheiro (2012, p. 33),

(...) antes de tudo, penso que, na qualidade de um professor, preciso estar sempre revendo minhas práticas. Além disso, se, (...), estou partindo do pressuposto de que a aprendizagem colaborativa pode, de fato, ocorrer no contexto escolar por meio do uso de ferramentas da internet, então, é necessário, a meu ver, ter algum conhecimento empírico para que esse pressuposto possa ser, de fato, confirmado, ainda que em meio a alguns percalços.

O professor só exercerá essa função de mediador se tiver conhecimento empírico, ou seja, conhecer os mecanismos necessários para a prática docente e, no caso do uso das tecnologias, ter o letramento digital, de modo a favorecer o desenvolvimento da competência dos alunos a partir de situações que possibilitem a construção do conhecimento. 
Importante ressaltar que o trabalho colaborativo já foi mencionado nos PCN (1998), ao tratar, por exemplo, da leitura colaborativa. Segundo o documento oficial,

A leitura colaborativa é uma atividade em que o professor lê um texto com a classe e, durante a leitura, questiona os alunos sobre os índices linguísticos que dão sustentação aos sentidos atribuídos. É uma excelente estratégia didática para o trabalho de formação de leitores, principalmente para o tratamento dos textos que se distanciem muito do nível de autonomia dos alunos. (BRASIL, 1998, p. 72)

As práticas colaborativas favorecem uma maior interação entre os sujeitos que participam do processo de ensino-aprendizagem, de modo que eles podem trocar ideias, discutir determinado assunto, buscar informações nas diferentes plataformas digitais, enfim, construir o conhecimento de forma em que todos os sujeitos tenham uma participação ativa. No entanto, para que esse processo se desenvolve, o professor precisa ter o conhecimento desse caminho que pode levar os alunos ao desenvolvimento das habilidade e competências necessárias para a construção do conhecimento.

De acordo com Perrenoud (2000), as novas tecnologias na área educacional podem ser consideradas como uma das competências necessárias no processo de ensino-aprendizagem. No entanto, exige-se que o professor tenha o letramento digital e seja seletivo e crítico, a fim que possa escolher os softwares adequados para a prática pedagógica. Para o autor, é necessária a observação, o pensamento hipotético dedutivo, a capacidade de memorização e classificação, além da análise dos textos em sua dimensão multimodal.

As tecnologias favorecem o estudo do texto numa perspectiva multimodal, ou seja, aquele que mobiliza simultaneamente uma série de linguagens. De acordo com Maingueneau (2015, p. 159-160), todo texto é multimodal, visto que "a comunicação ativa simultaneamente a produção de um fluxo sonoro e a de movimentos corporais associados”. De acordo com o estudioso francês,

A importância da dimensão icônica se traduz, assim, em dois níveis: de um lado, os enunciados verbais se incrustam nas imagens ou as imagens acompanham os textos; de outro, o próprio conjunto que 
as imagens e os enunciados verbais formam constitui também uma forma trabalhada em si mesma. (MAINGUENEAU, 2015, p. 160).

É possível afirmar que o advento das tecnologias favoreceu ao processo de ensinoaprendizagem uma nova concepção para o texto, que é considerado um iconotexto. O verbal e o não verbal estão conjugados e cada vez mais há um predomínio do não-verbal nos textos que circulam na $W e b$.

Essas concepções - texto, multimodalidade, novas tecnologias - precisam ser levadas às formações iniciais dos professores, como também nas continuadas, de modo que estes estejam preparados para desenvolver a prática pedagógica de modo a atender às necessidades da sociedade, fazendo com que a sala de aula seja o espaço de construção de conhecimento significativo para os sujeitos que dela participam.

Ainda em relação à multimodalidade, Dionisio e Vasconcelos (2013, p. 21 e 23) apontam que as interações humanas são mediadas por artefatos multimodais, acrescentando que, com o avanço das tecnologias, multiplicam-se as possibilidades de utilização das diversas linguagens. Segundo as autoras, a diversidade de gêneros e de situações comunicativas nas quais haja "combinação de recursos semióticos significa, portanto, promover o desenvolvimento neuropsicológico de nossos aprendizes" (DIONISIO e VASCONCELOS, 2013, p. 19).

Mayer (2001; 2009, apud DIONISIO e VASCONCELOS, 2013, p. 34 ) também comenta o potencial do desenvolvimento cognitivo do indivíduo na utilização de textos multimodais, devido à dupla capacidade de processamento de informações, por exemplo. Esta é uma das razões de considerarmos importante a inclusão dos recursos digitais no processo de ensino-aprendizagem, uma vez que potencializam o desenvolvimento cognitivo do aluno.

A inserção das novas tecnologias na prática docente oportuniza mudança de paradigma, o qual se refere à aprendizagem e não às tecnologias, que não podem ser um fim em si mesmas. Elas devem favorecer o processo de ensino-aprendizagem, uma estratégica 
que viabilize, de forma colaborativa e participativa, a construção do conhecimento. Segundo Perrenoud (2000, p. 139), ocorre uma passagem de "uma escola centrada no ensino (...) a uma escola centrada não no aluno, mas nas aprendizagens”. Exige-se nesse contexto uma reflexão sobre o papel do professor no processo de ensino-aprendizagem, o qual deve voltar-se mais para o "fazer aprender" do que para o ensinar. Configura-se a figura do professor-mediador, que leva o aluno, valendo-se dos recursos oferecidos pelas novas tecnologias, à construção do conhecimento de forma autônoma.

Para atingir esse propósito, há necessidade de (re)pensar a formação do professor. No Brasil, existem vários documentos que pautam a formação inicial do docente. Podemos citar a Lei de Diretrizes e Bases (LDB) e o Parecer do Conselho Nacional de Educação CP 9/2001, que trata das Diretrizes Curriculares Nacionais para a Formação de Professores da Educação Básica, mais especificamente em relação aos cursos de Licenciatura.

De acordo com a Lei de Diretrizes e Base (1996), no título VI, ao tratar a Educação Superior:

Art. 61. A formação de profissionais da educação, de modo a atender aos objetivos dos diferentes níveis e modalidades de ensino e as características de cada fase do desenvolvimento do educando, terá como fundamentos:

I - a associação entre teorias e práticas, inclusive mediante a capacitação em serviço;

É perceptível a preocupação que há em formar profissionais para a educação a partir da conciliação entre teoria e prática.

O Parecer 9/2001 afirma que a formação profissional deve ser vista como "a preparação voltada para o atendimento das demandas de um exercício profissional específico que não seja uma formação genérica e nem apenas acadêmica" (BRASIL, 2001, p. 23). Observa-se que o documento oficial destaca como característica inerente à atividade docente a preparação do futuro professor comprometida com a aprendizagem do aluno. A escola deve preparar o discente para a vida em sociedade, em todos os seus aspectos e, 
nesse sentido, a formação inicial do professor deve ser marcada pela associação entre teoria e prática.

Desde a publicação deste Parecer, há uma ênfase na concepção de uma escola voltada para a construção de uma cidadania consciente e ativa, de modo que o futuro professor, já no processo de formação inicial, torne-se um sujeito de discurso, capaz de posicionar-se criticamente em relação às demandas sociais e preocupado com a formação cidadã de seu aluno. De acordo com Kensky (2014, p. 73), "a revisão de currículos e práticas de formação é exigida pelas próprias associações profissionais que contabilizam o grande desgaste decorrente da necessidade de qualificação para a inserção de profissionais recémgraduados no mercado de trabalho.”. É inconcebível um professor entrar na escola básica sem ao menos as noções básicas do letramento digital, tendo em vista o contexto em que vive a sociedade contemporânea.

Embora alguns anos já tenham se passado desde a publicação do Parecer, a nova realidade sugerida pelo documento ainda é um dos grandes desafios ara a educação superior no Brasil. Há certa resistência em mudanças; infelizmente, ainda encontramos cursos de formação de professor presos apenas às questões teóricas, muitas vezes, longe da realidade do futuro professor e do aluno da escola básica. Como afirmamos, trata-se de uma postura daqueles que estão envolvidos no processo de ensino-aprendizagem no todo. E esse fato ainda é perceptível no tocante à inserção das novas tecnologias, seja na escola básica, seja nos cursos de formação inicial. Como aponta Kensky (2014, p. 68),

A cultura tecnológica exige a mudança radical de comportamentos e práticas pedagógicas que não são contemplados apenas com a incorporação das mídias digitais no ensino. Pelo contrário, há um grande abismo entre o ensino mediado pelas TICs - pratico em muitas das escolas, universidade e faculdades - e os processo dinâmicos que podem acontecer nas relações entre professores e alunos on-line.

A presença das mídias digitais na instituição escolar não é suficiente para mudar a postura do professor, do aluno, da comunidade escolar num todo. Faz-se necessário a mudança de implantação de uma política institucional que mobilize competências e habilidades 
que visem à construção do conhecimento mediada pelas diversas ferramentas oferecidas por essas mídias. O letramento digital também é condição sine qua non para atingir esse objetivo.

Para que os recursos tecnológicos estejam presentes no cotidiano escolar, é preciso que os sujeitos que estão inseridos nele os utilizem de forma eficiente. Torna-se importante a atualização constante do professor em relação às transformações pedagógicas, dentre elas a inserção das tecnologias. Nesse sentido, é preciso que haja não só a presença dessas tecnologias na formação inicial, como também na formação continuada de docentes, a fim de que eles estejam com competência para aproveitar os diversos recursos disponíveis nas diferentes plataformas pedagógicas, favorecendo um ensino colaborativo, ativo e significativo.

A formação inicial e continuada aliada aos recursos tecnológicos apresenta-se como potencial para que professores ampliem suas práticas de letramento digital, familiarizem-se com a textualidade e a produção de sentidos no meio digital e, acima de tudo, rompam com crenças ainda arraigadas no modelo de escola pautada pela transmissão e recepção de conteúdo. Essa nova postura do professor traz modificações nas formas de ensinar-aprender.

Entendemos por letramento digital a capacidade que o sujeito tem de responder às demandas sociais que envolvem a utilização de recursos tecnológicos e, também, da escrita pelo meio digital. Esse letramento vai além do conhecimento técnico. De acordo com Carmo (2003, p. 23), ele inclui

habilidades para construir sentido a partir de textos multimodais, isto é, textos que mesclam palavras, elementos pictóricos e sonoros na mesma superfície. Inclui também a capacidade para localizar, filtrar e avaliar criticamente informações disponibilizadas eletronicamente.

A partir dessa conceituação de Carmo, podemos inferir que um sujeito letrado digitalmente necessita de habilidade para construir sentidos a partir de textos que compõem palavras que se conectam a outros tetos, por meio de hipertexto e links, elementos pictóri- 
cos e sonoros. Ele também precisa ter a capacidade para localizar, filtrar e avaliar criticamente informações disponibilizadas eletronicamente e, ainda, ter familiaridade com as normas que regem a interação com outras pessoas por meio eletrônico. Ratificamos a ideia de que não basta ter os aparelhos eletrônicos digitais para que se realize trabalhos pedagógicos no processo de ensino-aprendizagem a partir da cultura digital.

Para Barton (1998 apud Xavier, 2007, p. 2) como existem vários tipos de letramento, o letramento digital seria um tipo e não um novo letramento imposto à sociedade hodierna pelas novas tecnologias. Segundo autor, os tipos de letramento mudam porque são situados na história e acompanham a mudança de cada contexto tecnológico, social, político, econômico ou cultural numa sociedade. O que tem ocorrido é uma adoção do tipo de letramento alfabético para o digital. Para Xavier, o "alfabético está servindo de apoio para a aprendizagem do letramento digital”. E completa Xavier (2007, p. 2):

O letramento digital implica realizar práticas de leitura e escrita diferentes das formas tradicionais de letramento e alfabetização. Ser letrado digital pressupõe assumir mudanças nos modos de ler e escrever os códigos e sinais verbais e não-verbais, como imagens e desenhos, se compararmos às formas de leitura e escrita feitas no livro, até porque o suporte sobre o qual estão os textos digitais é a tela, também digital.

Ressalte-se, portanto, a importância de o professor ser um sujeito letrado digitalmente, para que possa atuar de forma significativa no processo de ensino-aprendizagem, mediando a construção de conhecimento, tornando seu aluno autônomo para pesquisa, localizar, filtrar e avaliação criticamente as informações disponibilizadas eletronicamente.

\section{A formação docente: da teoria à prática}

Ao pensarmos o curso de formação inicial e também a continuada, é preciso considerar o papel fundamental que os professores formadores assumem neste processo, uma vez que precisam possibilitar os futuros professores vislumbrar novas metodologias nas práticas pedagógicas da escola básica. E, dentre essas metodologias, é possível pensar a 
inserção das novas tecnologias, como estamos defendendo neste artigo, a partir do momento em que há o letramento digital tanto dos formadores quanto dos futuros professores.

Para Carvalho (2003, p. 2), a mudança para um novo paradigma educacional está na superação do "ensino expositivo, centrado na capacidade do professor explicar o conteúdo proposto, para o ensino construtivista, centrado na capacidade de o aluno entender, (re)construindo um determinado conhecimento".

Uma possibilidade para o uso das tecnologias digitais na prática pedagógica diz respeito ao movimento de criação de texto. A palavra criar remete à ideia que leva à característica do próprio ser humano, ou seja, envolve ação, imaginação, sensibilidade; ela traduz, ainda, a estética e, mais uma vez, caminhamos pela trilha da multimodalidade. E considera, ainda, o meio, ou, na concepção de Maingueneau (2011, 2015) no mídium, envolvendo uma série de recursos capazes de dar funcionalidade ao que é criado. Nesse sentido, a criação está, também, ligada às tecnologias digitais.

A migração do livro impresso para o digital constitui-se em uma das reinvenções do mercado editorial desde os tempos de Gutenberg. A internet transformou não só o modo como se consome cultura, como também a maneira como esta é produzida. Mais do que um novo suporte de leitura, o livro eletrônico vem impactando o processo de criação, editoração, distribuição e consumo de textos. Como diz Chartier (2009), passamos do leitor ao navegador, uma vez que o leitor é capaz de "navegar por vários mares digitais".

De acordo com Teixeira (2015, p. 33),

A invenção do livro digital, adquirido diretamente da internet e armazenado em computadores ainda sofre influências da tradição da impressão, mas, segundo El Far (2006), a tela do computador oferece uma nova dinâmica de leitura e disposição do conteúdo por meio de interatividade, navegação não-linear, sistemas de busca por palavra-chave etc.

Existem uma infinidade de plataformas que possibilitam a aplicação de novo fazer pedagógico, abrindo espaço para que o aluno seja sujeito na construção do conhecimento. 
Dentre elas, podemos citar a plataforma Openzine e bookr, que se constituem em aplicativos cuja finalidade é tratar de temas de interesse coletivo. Tanto um quanto o outro exigem um trabalho coletivo, em que os alunos podem se dividir em grupos e criar uma dinâmica colaborativa para a produção, revisão, formatação, ilustração e publicação final, tudo por meio das tecnologias digitais.

O Openzine possibilita a construção colaborativa de uma revista, uma vez que as tarefas de redator, revisor, editor, dentre outras, levam à divisão das diferentes etapas de escrita de uma revista. Há a possibilidade para os alunos trabalhem com uma variedade de temas e gêneros de discurso, de acordo com o objetivo estabelecido para a execução da atividade. Além disso, o professor há de orientar os alunos em relação à necessidade do planejamento e do conteúdo a ser colocado nos diferentes gêneros que constituirão a revista.

No processo de formação inicial ou continuada, a partir de uma determinada área do conhecimento - Artes, Língua Portuguesa, História, Geografia, dentre várias - esta ferramenta possibilita aos alunos, futuros professores, a elaboração da revista, desde a escolha da capa, o layout da paginação, até a escrita dos textos que constituirão a Revista, fazendo uso das imagens, cores, letras etc. E não há necessidade de software sofisticado para a construção da Revista.

Valer-se de Openżine no processo de formação do professor leva este a vislumbrar os mecanismos que constituem os diferentes gêneros de discurso que constituem a revista on-line. Importante ressaltar que o trabalho com gêneros diversificados possibilita ao futuro professor envolver-se não só com os mecanismos de linguagem, como também a perceber os aspectos multimodais que permeiam a revista.

Booker constitui-se em uma ferramenta que favorece a criação de um livro virtual, com imagens, inclusive. Ela possibilita também a associação de imagem e palavra. O livro é criado com imagens do Flickr e texto e depois pode ser publicado, por exemplo, em blogues criados pelos próprios aluno. O aplicativo faz com que o aluno seja autor, sujeito ativo na construção do texto. 
Com o livro digital, é possível dizer que houve uma maior democratização do livro, que chegar com maior facilidade a vários leitores por meio da web. Ele possibilita uma série de maneiras de realizar a leitura, promovendo uma maior interatividade entre leitor, autor e texto. Ele é projetado num novo mídium, possibilitando novos efeitos de sentido para a leitura.

Por meio desta atividade, os alunos-autores passam a ser os principais agentes da cadeia produtiva a cuidarem do conteúdo - tanto verbal quanto não verbal - que constituirá o livro. O professor, nesta atividade, abre espaço para uma nova forma de se contar história, com imagens, cores, links, hiperlinks, enfim, todos os recursos oferecidos pelas tecnologias digitais.

De acordo com Procópio (2010), existe uma série de elementos que caracterizam o e-book, que podem se configurar no aplicativo Bookr. Dentre elas, podemos citar: marcadores de página e busca rápida dessas marcações; controle ajustável de luminosidade; ajuste de tamanho e tipo das fontes, fazendo com que o autor e o leitor da história possam interagir com o texto.

A construção de um livro digital pelos alunos, por meio do aplicativo Bookr, corrobora para a ideia de que

Perante um novo paradigma, em que passámos de uma cultura alfabética, textual e impressa para uma cultura em que o texto passou a ser encarado como uma unidade de comunicação com diferentes formas de expressão, parece-nos, pois, imprudente restringir a promoção da leitura recreativa ao suporte impresso ou apenas ao formato literatura, assim como não podemos ignorar o poder que as tecnologias exercem sobre o atual leitor, um nativo digital (RAMOS, 2015, p. 1)

Como dissemos, esta atividade leva o aluno a se tornar um sujeito-autor-leitor, pois, para produzir o texto, ele demonstra uma leitura de mundo, posicionando-se, colocandose como sujeito ativo diante de uma possível leitura de mundo refletida na história criada, articulada, organizada, programada e editada. 
A elaboração de um livro incluir, portanto, inclui atividade de animação da leitura, que exigem do aluno um envolvimento com a leitura e a produção do texto, atribuindo uma nova concepção para o ato de ler a realidade, materializada no texto resultado da ação conjunta entre os sujeitos envolvidos no processo de ensino-aprendizagem. As tecnologias digitais favorecem essa postura do aluno diante do mundo, dentro dos limites da escola, permitindo a ele que estabeleça um elo entre a realidade escolar e a extraescolar.

\section{Palavras finais}

Ao longo deste artigo procuramos evidenciar possíveis aspectos da interface entre novas tecnologias, multimodalidade e formação inicial/continuada de professor. A reflexão trazida a partir desta interface leva-nos a mostrar quão importante, no contexto atual, é a inserção das tecnologias no processo de ensino-aprendizagem, o que implica também a formação do professor, seja inicial, seja continuada.

Educação de qualidade depende de uma formação que concilie teoria e prática, levando o futuro professor a captar melhor as condições sociais, culturais, intelectuais de sua própria prática. E esse fato refletirá na prática docente na escola básica.

O professor precisa ser um pesquisador, ter autonomia, para saber conduzir o trabalho a ser desenvolvido com seus alunos. Como aponta Kensky (20014, p. 71),

não basta, portanto, a utilização das tecnologias avançadas como repositórios de conteúdos. Não basta também a ação distante e indiferenciada do professor, em broadcasting, sem o estabelecimento de vínculos que estimulem e desafiem os estudantes a avançar nos estudos e a superar desafios.

A escola ainda tem muitos desafios a serem enfrentados e um deles é levar o professor a refletir sobre a importância que as tecnologias assumem no cotidiano do ser humano, na vida em sociedade.

A partir do que fora exposto neste artigo, o uso de ferramentas no processo de formação inicial e/ou continuada de professor potencializa a interação entre os sujeitos envolvidos na prática pedagógica e o conhecimento a ser construído. Além disso, ele apura 
a possibilidade da construção do conhecimento de forma colaborativa e é nesse sentido que a aprendizagem potencializa-se, na medida em que diferentes ferramentas, as quais se voltam para um trabalho contextualizado e interativo, são utilizadas. Há de se considerar, ainda, que as duas ferramentas por nós apresentadas facilitam a elaboração e execução de diferentes atividades, que se tornam dinâmicas e motivadoras para as aulas.

\title{
INITIAL AND CONTINUING TEACHER TRAINING FACING DIGITAL TECHNOLOGIES
}

\begin{abstract}
This article proposes a reflection on the interfaces between initial and continuing teacher training and the use of technologies in this process. The technologies are increasingly present in the daily life of individuals and, consequently, must be part of the teaching-learning process so that the school gets closer to reality in which are inserted the subjects who participate in it. Through a qualitative approach, we bring concepts about discourse, multimodality, digital literacy and teacher training and, from these, we suggest the use of two applications for the construction of knowledge, whether in initial or continuing education. The theoretical basis for this study was Perrenoud (2000), Kensky (2014), Carmo (2003) and Xavier (2007) on digital literacy, as well as Dioniso e Vasconcelos (2013) and Maingueneau (2015) in multimodality. For an approach to the interface between teacher training and new technologies, we also use official documents such as Opinion 9/2001 of the National Education Council, the National Curricular Parameters (1998) and Laws of Guidelines and Bases (1996), which support our reflections. From what we present in this article, it is possible to affirm that quality education depends on a formation that conciliates theory and practice, leading the future teacher to better grasp the social, cultural, and intellectual conditions of his own practice. And this fact will reflect on teaching practice in elementary school.
\end{abstract}

KEYWORDS: Teacher training; Digital Literacy; Digital technologies.

\section{REFERÊNCIAS}

BRASIL, Ministério da Educação. Parâmetros curriculares nacionais do ensino médio. Brasília, DF: MEC, 2000 .

BRASIL, Ministério da Educação. Conselho Nacional de Educação. Parecer CNE/CP 009/2001. Dispões sobre Diretrizes Curriculares Nacionais para a formação de Professores da Educação Básica, em nível superior, curso de licenciatura, de graduação plena. Disponível em http://www.mec.gov.br. Acesso em 15 jan. 2006.

BRASIL. Ministério da Educação. Secretaria de Educação Fundamental. Parâmetros curriculares nacionais: Língua Portuguesa. Brasília, DF: MEC/SEF, 1997.v.10.

BRASIL. Lei de Diretrizes e Bases. Brasília, DF, 1996 
CARMO, Josué G. Botura. O letramento digital e a inclusão social. Disponível em: http://paginas.terra.com.br/educacao/josue/ Acesso em: 17 Abr 2008.

CARVALHO, A. M. P. O que há em comum no ensino de cada um dos conteúdos específicos. In: . (Coord.). Formação continuada de professores: uma releitura das áreas de conteúdos. São Paulo: Pioneira Thomson Learning, 2003. p. 1-15.

DIONÍSIO, Angela Paiva e VASCONCELOS, Leila Janot. "Multimodalidade, gênero textual e leitura" in BUNZEN, Clecio e MENDONÇA, MÁRCIA (orgs.). Múltiplas linguagens para o ensino médio. São Paulo: Parábola, 2013, p. 19-42

KENSKY, Vani Moreira. Tecnologias e tempo docente. Campinas: Papirus, 2014.

MAINGUENEAU, Dominique. Discurso e Análise do Discurso. São Paulo: Parábola, 2015.

PERRENOUD, Pierre. Dez novas competências para ensinar. Porto Alegre: Artes Médicas, 2000 .

XAVIER, Antonio C. dos Santos. Letramento Digital e Ensino. Disponível em : http://www.ufpe.br/nehte/artigos/Letramento $\% 20$ digital $\% 20 \mathrm{e} \% 20$ ensino.pdf Acesso em 07 de maio de 2019.

PROCÓPIO, Ednei. O livro na era digital - o mercado editorial e as mídias digitais. São Paulo: GIZ Editorial, 2010.

Recebido em: 28/05/2019. Aprovado em: 25/07/2019. 